\title{
Optimization of process parameters towards the manufacturing of twill woven Glass /Epoxy -nano clay composite through hand-layup technique
}

\author{
Dr.B.Senthil Kumar \\ Asst. Professor, Department of Rural Industries and Management, \\ The Gandhigram Rural Institute-DU
}

\begin{abstract}
The Twill structured Glass woven matt was prepared through weaving process to produce the nanocomposite material along with the epoxy(SC-15) matrix component with the additional montmorillonite based nanoclay reinforcement structure. Different weight percentages of nanoclay was mixed such as $1.5 \%, 2.5 \%$ and $3.5 \%$,so as to analyse the effects of nanocaly particle enforcement on tensile properties of the composites. Sonication process was utilized to produce the thorough mixture of nanoclay and epoxy resin. The nanophased epoxy was then used to manufacture twill woven Glass/epoxy nanocomposites using hand-layup process. A 3-factor,3-level Box-Behnken design was used to derive a second order polynomial equation and construct contour plots to predict responses. The independent variable of this research was percentage of nanoclay content, woven matt areal density $\left(\mathrm{g} / \mathrm{m}^{2}\right)$ and resin stirrer speed(rpm).The SEM and XRD analysis was done to understand the nanoclay dispersion on the matrix and fracture analysis. It is concluded that up to $3.5 \%$ concentration of nano-clay composition the tensile strength of the composite increasing after that the strength would be decreased due to agglomeration of nanoclay structures
\end{abstract}

Key words-Nanocaly, Epox composite,Glass fibre,Woven matt

\section{Introduction}

The term nanocomposite is defined as polymer composite produced through two or more component material where at least one phase of material should be in the range of nano scale [7]. In the case of polymer usually the resin component is mixed with inorganic nanoparticle in addition to the regular reinforcement for improving the functional properties of the composites [2,15]. This improvement in the functional properties of the composite occurs due to the unique phase morphology and the interfacial properties of the nanoclay reinforcement[13].Nanoclay one of the low cost material possess highest tensile modulus and more suitable for reinforcement component in polymer composites and other suitable reinforcement such as nanotubes, nanoclays, silica particles and electrospun polymeric nanofibers etc[6]. Montmorillonite based nanoclay structure have 2to-1 layered smectile clay mineral with a platey structure[13].Since Organo treated montmorillonite clay creates high interfacial bonding between the polymer ,it is preferably used as nanofiller[8].Glass fibre reinforced composites widely used in industrial application ,but still suffered due to delamination, matrix cracking and fibre pullout etc..[1]. This form of defects can be removed by interfacing high stiffer nanoclay in addition to the formal reinforcement.

\section{Mechanical properties of Nano composites}

Kornmann et al. (2005) studied the influence of inorganic layered silicate reinforcement on the epoxy matrix composite and reported that $10 \% \mathrm{wt} \%$ of reinforcement increased the young modulus by $54 \%$. Haque et al. (2003) Prepared the nanocomposite using addition of 1\% wt\% nanoclay reinforced with Glass/epoxy structures through vacuum Assisted Resin Infusion Moulding(VARIM) and reported that flexural strength, shear strength, fracture toughness were improved by $23 \%$ to $25 \%$. This property changes was attributed that due to higher modulus of nonoclay, higher interfacial areas and improved bond strength between the nanoclay with the epoxy resin. 1-3 wt\% silence modified clay (SMC) in to the regular polymer composite material and showed the improvement in tensile strength by $25 \%$ and also concluded that the further addition of SMC reduced the mechanical strength of the composite[12]. They also studied the fracture surface of the composites and found that numerous micro cracks, which could have been generated at the interface due to exfoliated clay layers. Nanoclay in different weight percentage $(1 \%, 2 \%$ and $3 \%$ by weight ) with woven carbon/epoxy matrix structures through vacuum Assisted Resin Infusion Moulding(VARIM) and analysed the effects of nanoclay addition on flexural properties of the composites[5]. The flexural strength and flexural modulus of all specimens were increased up to $2 \%$ nanoclay loading and then decreased marginally with increase in clay content. The addition of nanoclay in woven carbon fabric-epoxy matrix composites reduced the impact damage and resistance to damage progression[10]. 


\section{Materials and methods}

Diglycidly ether of bisphenol-A (DGEBA) based epoxy (SC-15) was procured from GVR enterprises, Madurai,India. The glass fiber was purchased from ACME Fibre, Chennai in the form of filament and then weaving process was carried out at Laboratory of Gandhigram Rural university through table top hand weaving machine with a density of $610 \mathrm{~g} / \mathrm{m}^{2}$.

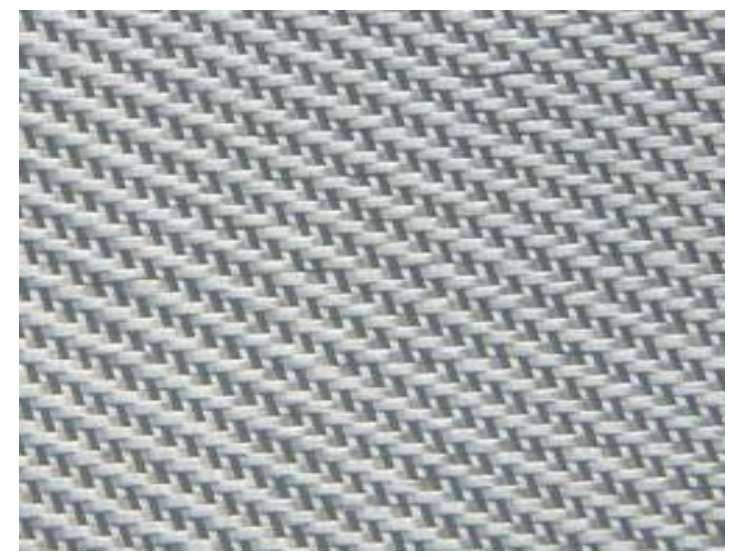

Fig.1 Twill woven Glass matt

Nano scaled Organo modified montmorillonite (MMT) was sourced from GVR enterprises, Madurai, India and a steel mould of $300 \mathrm{~mm} * 300 \mathrm{~mm} * 5 \mathrm{~mm}$ was fabricated in Gandhigram rural institute workshop.

\section{Preparation of epoxy/clay nanocomposites}

As per the sampling plan the three different nanoclay concentrated composite samples (1.5\%, 2.5\% and 3.5\%) were prepared. As reported by Bernd Wetzel etal (2003) epoxy resin should be mixed well with the nanoclay component before mixing with glass matt reinforcement. The mixing processes were performed using mechanical stirrer. Then $10 \%$ (by weight of the resin) hardener was added into the epoxy/nano mixture . Hand lay-up method was followed to produce the laminate through woodern mould with the dimension of $300 \mathrm{~mm} * 300 \mathrm{~mm} * 10 \mathrm{~mm}$. Polyvinyl alcohol (PVA) coated aluminium sheet was laid on mould cavity. Stage by stage the woven glass mat was placed on a mould and the corresponding epoxy/ nanoclay resin mixture with the curing agent was poured on each ply of glass fibre mat. The resin spreading roller was used to achieve uniform distribution of resin mixture. The laminate was allowed to cure for 24 hours. Post curing was carried out at $120^{\circ} \mathrm{C}$ for 4 hours and further cool down to room Temperature

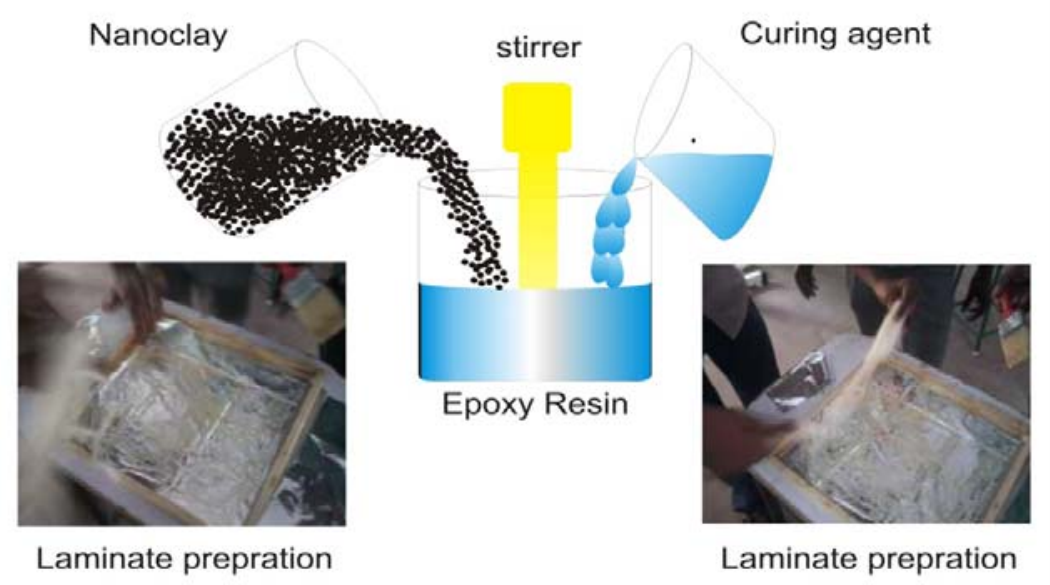

Fig.2 Preparation of epoxy/clay nanocomposites 


\section{Design of Experiments (DOE) for analysing optimum process parameters}

Optimization of process parameters are not only essential to increases the efficiency of production but also towards increasing the product quality. Since the polymer composite production process is one of the multivariate problem, the response surface methodology (RSM) is a simple tool for analysing, improving and optimizing of the process variables.

Without conducting the all possible experiments, DOE can also reflect the response of the interconnected factors over wide range of values and generate the regression equation, which serves as model to predict the other combination of predicted values(Anderson, M. 1997).The effect of composite manufacturing parameters on tensile properties of epoxy/ nanocomposites through RSM method. Three process factors have been selected for this research work by conducing trial study such as: (i) nanoclay content (wt \%), (ii) woven matt areal density (GSM) and (iii) stirrer speed (rpm).

So the tensile strength of the nanocomposite is a function of nanoclay content (A), woven matt areal density (B) and stirrer speed $(\mathrm{C})$ and it can be expressed as

$\mathrm{TS}=\mathrm{f}(\mathrm{A}, \mathrm{B}, \mathrm{C})$

The Specific first order polynomial equation is written as $\mathrm{TS}=\mathrm{b} 0+\mathrm{b} 1(\mathrm{~A})+\mathrm{b} 2(\mathrm{~B})+\mathrm{b} 3(\mathrm{C})$

Where $\mathrm{b} 0$ is the average of responses and b1, b2, b3 are the co-efficient that depend on the respective main and interaction effects of the process parameters. In order to estimate the regression co-efficient, experimental design techniques are utilized and the box behnken experimental design was used to fit the above polynomial equation

Table 1: Process parameter and its range

\begin{tabular}{|c|c|c|c|}
\hline Process parameter & $\mathbf{- 1}$ & $\mathbf{0}$ & $+\mathbf{1}$ \\
\hline Nanoclay content in \% & 1.5 & 2.5 & 3.5 \\
\hline Woven matt density(g/m $\left.{ }^{2}\right)$ & 650 & 700 & 750 \\
\hline Stirrer speed(rpm) & 800 & 850 & 900 \\
\hline
\end{tabular}

According to the table no.1 three process parameters were selected and its ranges such as -1 level,0level and +1 level .On the basis of pilot experiments, the ranges of nanoclay content, woven matt density (GSM) and stirrer speed(rpm) were chosen as 1.5\%-3.5\%, 650-750 GSM and 800-900 rpm, respectively.

Table 2 : Experimental run as per Box benhken design

\begin{tabular}{|c|c|c|c|c|c|}
\hline Run & S.No & $\begin{array}{c}\text { Nanoclay } \\
\text { content in \% }\end{array}$ & $\begin{array}{c}\text { Woven matt } \\
\text { density }\left(g / \mathbf{m}^{2}\right)\end{array}$ & $\begin{array}{c}\text { Stirrer } \\
\text { speed(rpm) }\end{array}$ & $\begin{array}{c}\text { Tensile } \\
\text { Strength (Mpa) }\end{array}$ \\
\hline 3 & 1 & 1.5 & 750 & 850 & 246 \\
\hline 13 & 2 & 2.5 & 700 & 850 & 294 \\
\hline 9 & 3 & 2.5 & 650 & 800 & 268 \\
\hline 1 & 4 & 1.5 & 650 & 850 & 212 \\
\hline 2 & 5 & 3.5 & 650 & 850 & 254 \\
\hline 7 & 6 & 1.5 & 700 & 900 & 245 \\
\hline 6 & 7 & 3.5 & 700 & 800 & 263 \\
\hline 15 & 8 & 2.5 & 700 & 850 & 287 \\
\hline 12 & 9 & 2.5 & 750 & 900 & 293 \\
\hline 10 & 10 & 2.5 & 750 & 800 & 298 \\
\hline 11 & 11 & 2.5 & 650 & 900 & 237 \\
\hline 4 & 12 & 3.5 & 750 & 850 & 275 \\
\hline 14 & 13 & 2.5 & 700 & 850 & 254 \\
\hline 5 & 14 & 1.5 & 700 & 800 & 228 \\
\hline 8 & 15 & 3.5 & 700 & 900 & 262 \\
\hline
\end{tabular}


As per table no. 2 the experiments were conducted and tensile testing of samples were carried out according to ASTM D3039 .The optimum response was studied using RSM technique. Through Design expert package the coefficients were found and the final mathematical expression of the relationship to composite tensile strength is shown below

Tensile strength $=18.37917+15.37500 *$ Nanoclay content in $\%+0.35250 *$ Woven matt $\operatorname{density}(\mathrm{g} / \mathrm{m} 2)-$ $0.050000 *$ Stirrer speed(rpm)

The results of analysis of variance (ANOVA) for Eq.(1) are shown in Table no.3

Table 3: ANOVA for fitted model

\begin{tabular}{|c|c|c|c|c|c|c|}
\hline Source & $\begin{array}{c}\text { Sum of } \\
\text { squares }\end{array}$ & Df & $\begin{array}{c}\text { Mean } \\
\text { square }\end{array}$ & F value & p-value & Prob > F \\
\hline Model & 4426.25 & 3 & 1475.417 & 3.507822 & 0.0429 & Significant \\
\hline $\begin{array}{c}\text { A-Nanoclay } \\
\text { content in \% }\end{array}$ & 1891.125 & 1 & 1891.125 & 4.496174 & 0.050 & Significant \\
\hline $\begin{array}{c}\text { B-Woven matt } \\
\text { density(g/m2) }\end{array}$ & 2485.125 & 1 & 2485.125 & 5.908417 & 0.0334 & Significant \\
\hline $\begin{array}{c}\text { C-Stirrer } \\
\text { speed(rpm) }\end{array}$ & 50 & 1 & 50 & 0.118876 & 0.7368 & Not significant \\
\hline Residual & 4626.683 & 11 & 420.6076 & & & \\
\hline Lack of Fit & 3714.017 & 9 & 412.6685 & 0.904314 & 0.6280 & not significant \\
\hline Pure Error & 912.6667 & 2 & 456.3333 & & & \\
\hline Cor Total & 9052.933 & 14 & & & & \\
\hline
\end{tabular}

The Value "Prob> F"' less than 0.05 indicates that the relationship is significant. From the above table, it is understood that the relationship equation (1) is found to be adequate at $95 \%$ confidence level. The model value of $\mathrm{F}$ is 3.507 refers that the relationship is significant. In this case A and B are significant. The 'Lack of Fit Fvalue' of 0.904 refers that the Lack of Fit is not significant relative to the pure error. There is $62.80 \%$ chance that a "Lack of Fit F-value"' this large could occur due to noise. A coefficient of determination (R2) value of this equation is 0.931 , which showed that the equation was highly reliable. Subsequently to examine the validity and conformity of the model fit, the normal probability curve of residue was drawn with observed value and predicted value
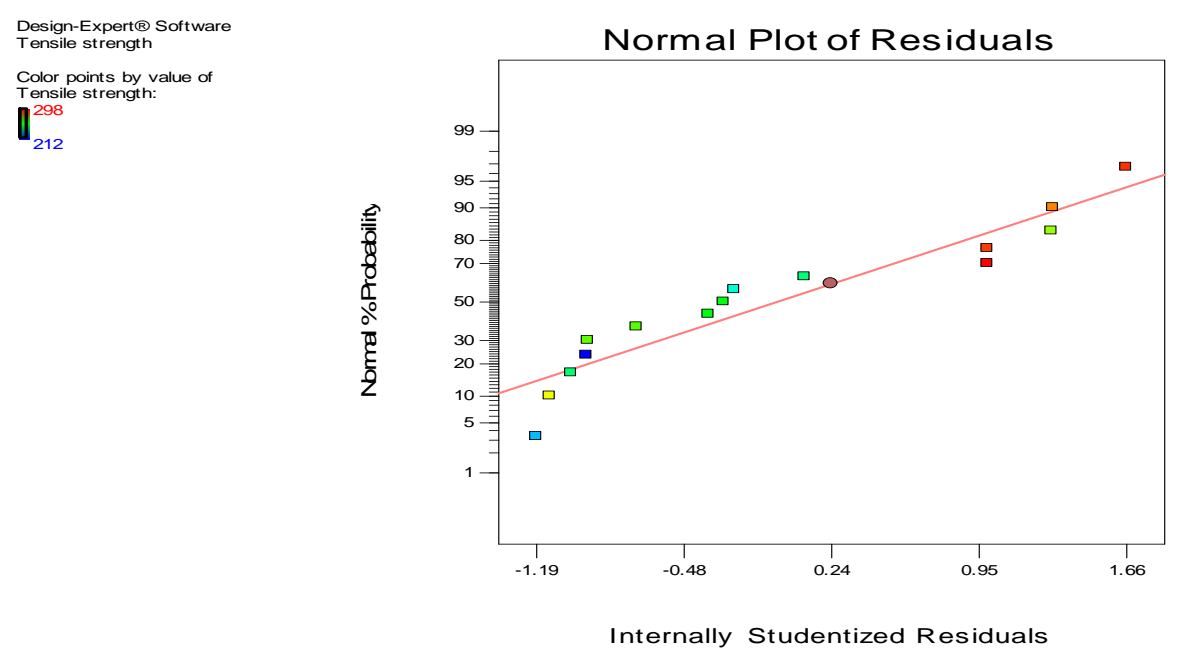

Fig 3. Normal probability curve of residues 


\section{Effects of process parameters on tensile strength of the nanocomposite}

The estimated value of response on tensile strength with respect to its selected process parameters such as woven matrix density, \% of nanoclay content and stirrer speed are shown in Fig. 4,5\&6.

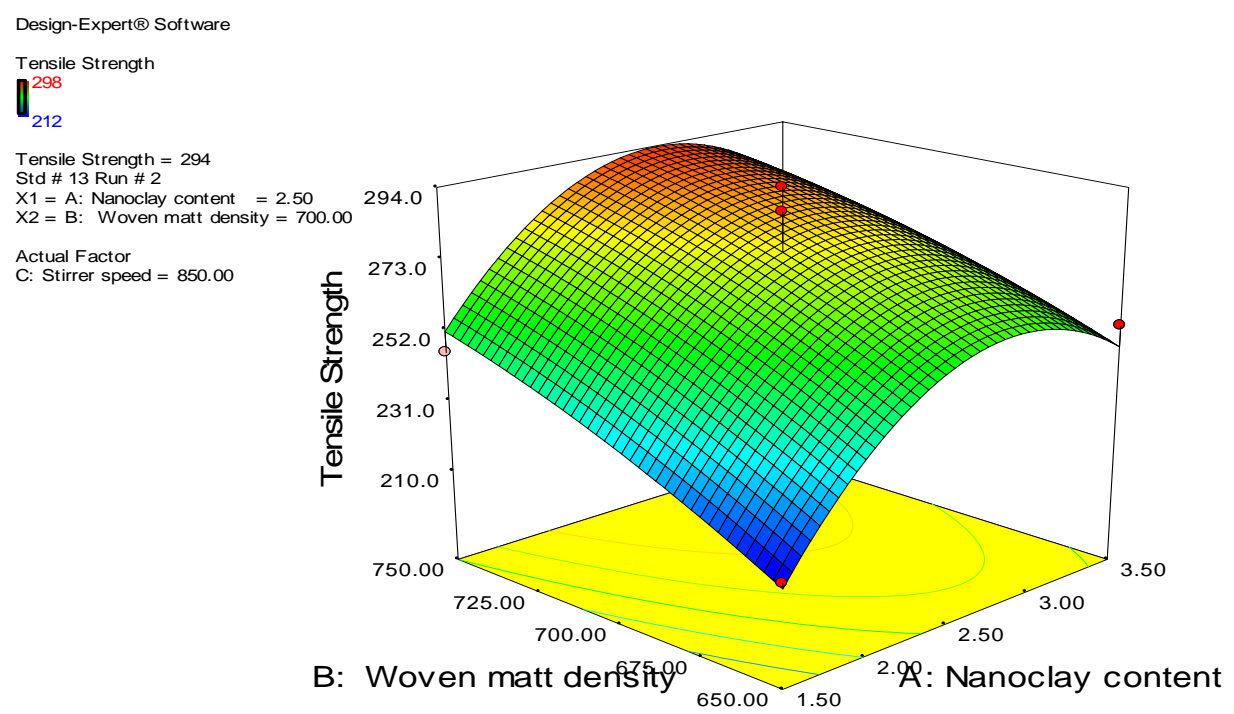

Fig.4 3D surface plot for the tensile strength of nanocmposite by nanoclay content as a function of woven matt density and stirrer speed at a fixed value of $850 \mathrm{rpm}$

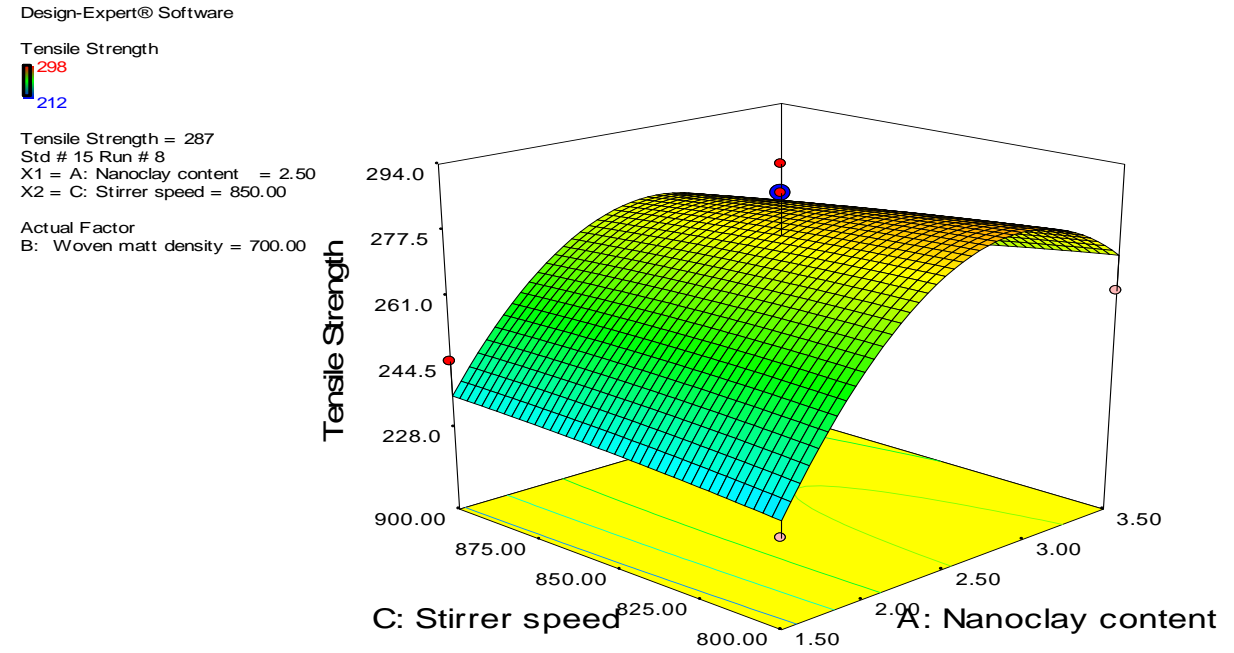

Fig.5 3D surface plot for the tensile strength of nanocomposite by nanoclay content as a function of stirrer speed and nanoclay content at a fixed value of $2.5 \%$ 


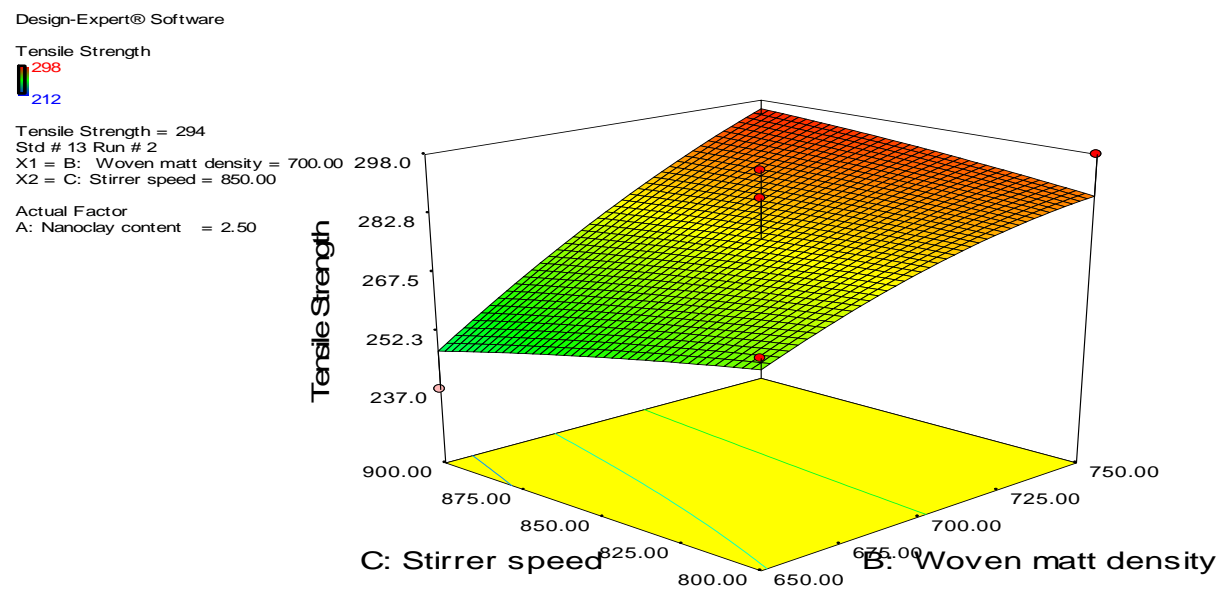

Fig.6 3D surface plot for the tensile strength of nanocomposite by stirrer speed as a function of woven matt density and nanoclay content at a fixed value of $2.5 \%$

The highest tensile strength was attained with 2.5\% clay content,700 gsm fabric density,800 rpm stirrer speed. In Fig.2 shown that up to 2.5 \% clay content the tensile strength was achieved as maximum level. In Fig.3 shown the highest response was achieved with $800 \mathrm{rpm}$ stirrer speed afterwards there would be a steep decrease in tensile strength of the composite. In Fig.4. It shows that the tensile strength was maximum upto 700 GSM. It is expected that the tensile strength will increase from $800 \mathrm{rpm}$ to $900 \mathrm{rpm}$ due to higher degree of cross linking will occur between these resin component to matrix component. Whereas the strength was decreased drastically from the stirrer speed increased from $800 \mathrm{rpm}$ to $900 \mathrm{rpm}$, this is due to high inertial forces in the speed of mechanical stirrer and caused the clay layers to break rather than separate. In the same way the woven matt areal density increases up to 700 gsm the tensile strength of the resultant composite was increased ,more than that the strength was decreased, which was interpreted that the higher amount of fibre volume fraction will cause insufficient fibre matrix bonding.

\section{SEM Analysis of Nanoclay}

The fracture surfaces of the deformation and failure behaviour of the samples were investigated using magnified level of scanning electron microscopy (SEM). The SEM analysis was carried out with Hitachi S-3400N at an acceleration voltage of $120 \mathrm{kV}$. To do this task the surface of the sample was coated with a thin gold film to increase the surface conductivity. Fig.7 shows the dispersion of nanoclay particles in the matrix component of nanocomposite having $2.5 \%$ nanoclay concentration. It shows that the clay particles are finely dispersed throughout the matrix portion in the form of small aggregates. But, higher magnification image indicates the maximum nanoclay exfoliated structure due to well dispersed individual layers. This behaviour could be due to the presence of $\mathrm{OH}$ groups in nanoclay, which in turn increase the chemical affinity with epoxy matrix. This phenomenon induces the nanoclay particles to form the small aggregation or even separate particles. But in the case of $3.5 \mathrm{wt} \%$ nanoclay concentrated composites shows that higher quantum of aggregates as shown in Fig.8, which is due to intercalation among the nanoclay structures and this leads to reduce the mechanical properties of the final material.

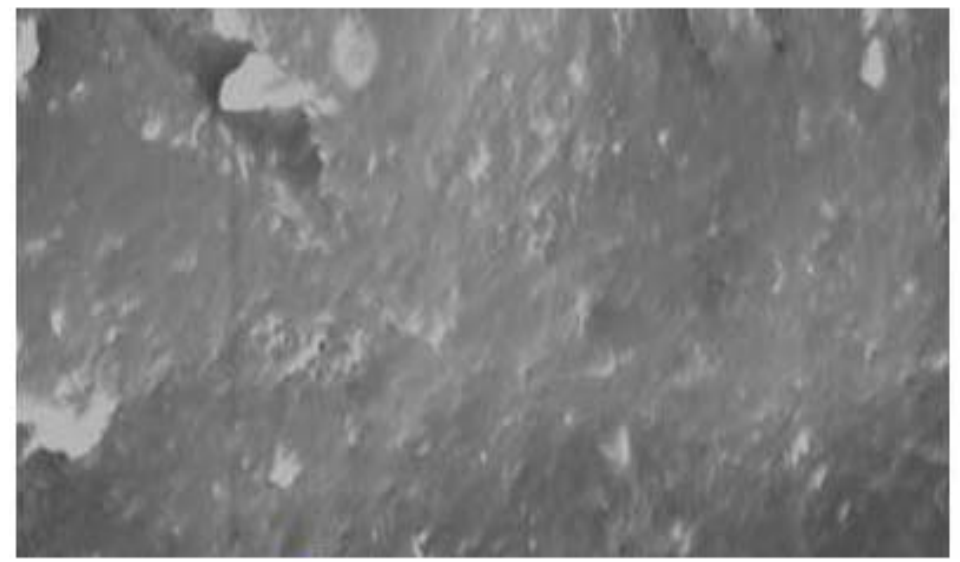

Fig. 7. SEM microstructure of $2.5 \mathrm{wt} \%$ nanoclay 


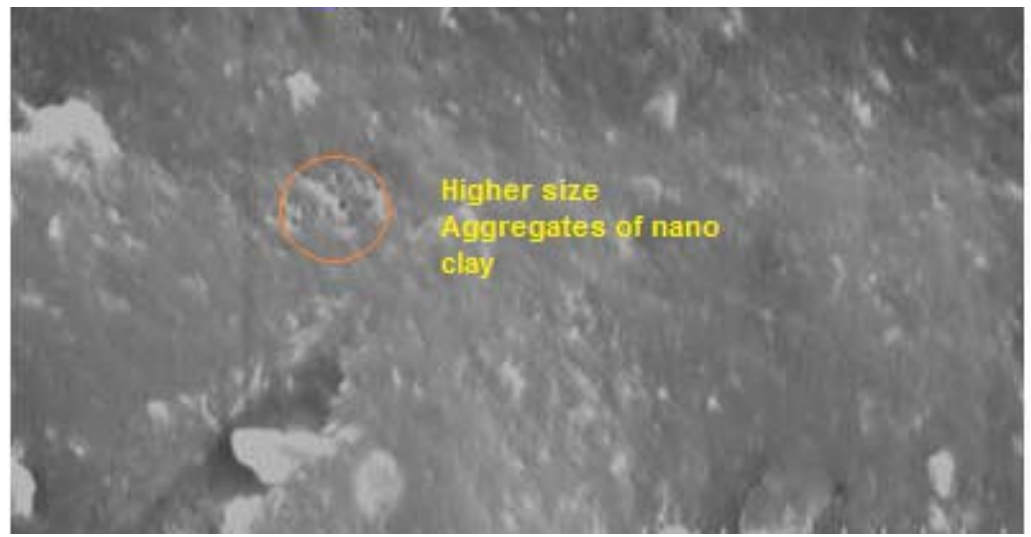

Fig.8. SEM microstructure of $3.5 \mathrm{wt} \%$ nanoclay

The fractured surfaces were examined in order to understand the fracture behaviour of the nanocomposites during mechanical testing. The Fig.9 indicated the fracture surfaces of $2.5 \mathrm{wt} \%$ nanocomposite shows that much rougher fracture surface due to the addition of nanoclay into the epoxy matrix. This fracture surface roughness attributes that the resistance to crack propagation is maximum, whereas in the case of pure glass/epoxy composite showed (Fig.10) that matrix cracking, delaminations and fibre damage due to lack of crack propagation. This effect of higher strength to failure leads to improved tensile strength of nanocomposites.

non damaged fibre after tensile testing

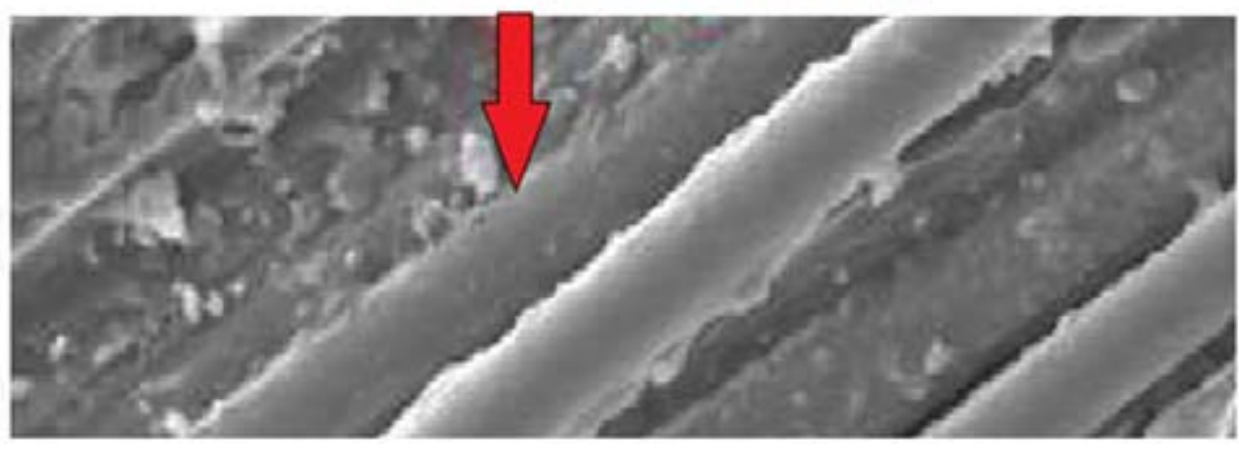

Fig.9.SEM fractured sample of $2.5 \mathrm{wt} \%$ nanoclay

Damaged glass fibre in the woven matt

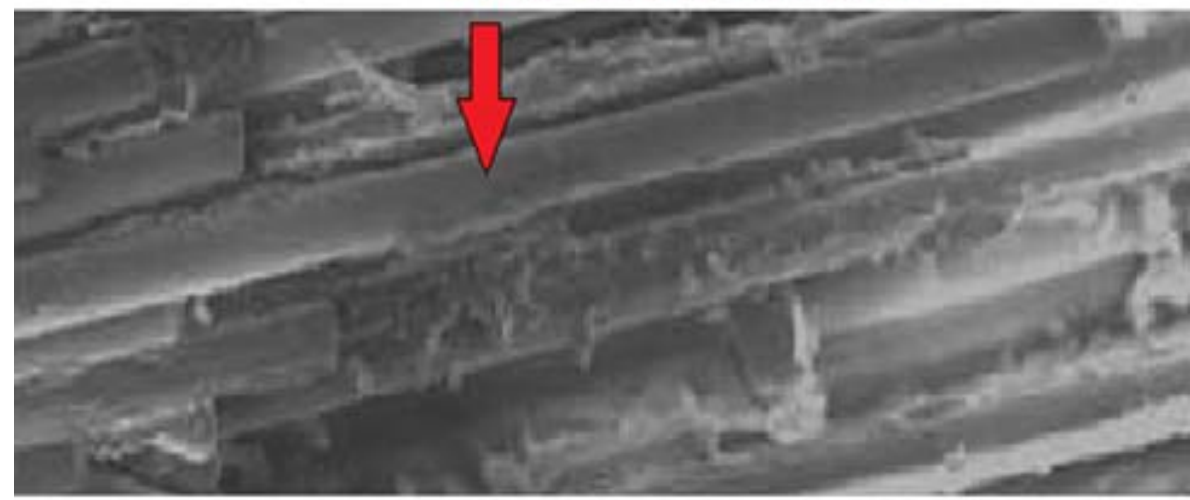

Fig.10. SEM fractured sample of Pure nanoclay 


\section{X-ray diffraction (XRD) patter of nanocomposites}

X-ray diffraction (XRD) was performed to evaluate the degree of intercalation/ exfoliation of nanocaly inside the composites. The following figures show X-ray diffraction patterns for the nanoclay and nanocomposites with varying concentration of clay content.

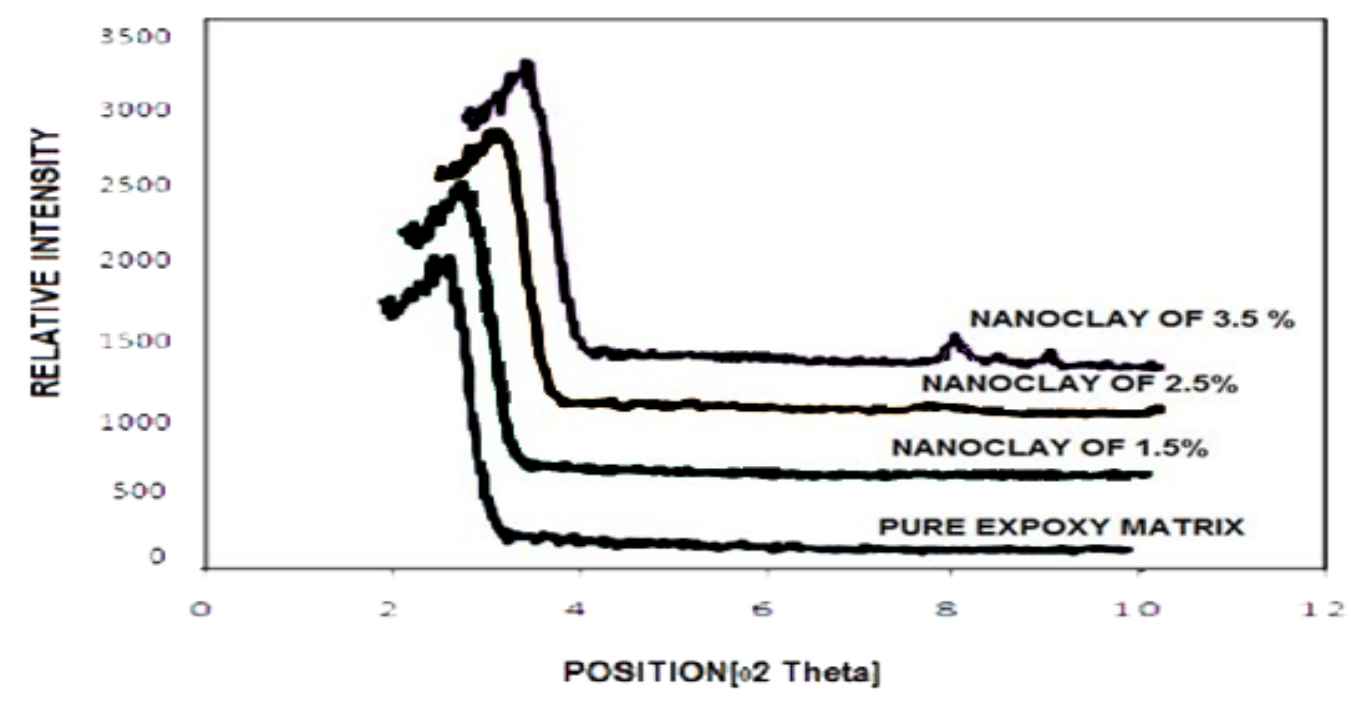

Fig.11.XRD pattern of naocomposite with varying \% of nanoclay

The XRD pattern indicated in Fig.9 shows that absence of characteristic clay (d001) diffraction peak except $3.5 \mathrm{wt} \%$ of nanoclay concentration ,which indicates that nanoclay was uniformly dispersed into the epoxy resin and it is confirmed that the formation of an exfoliated nanocomposite structure. But in the case of $3.5 \mathrm{wt} \%$ nanoclay sample shows broad peak presence in the characteristic clay (d001) diffraction peak which indicate an intercalation among the nanoclay structures due to higher percentage of nanoclay addition. This phenomenon leads to the formation of exfoliation structure. This is also understood that due to the strong tendency attractive nature of nanoclay particles among themselves promotes agglomeration and increased viscosity of resin when mixed with nanoclay. Hence, the property of nanocomposites depended on the concentration of nanoclay content in the polymer matrix

\section{Conclusion}

The nanoclay was used as effective reinforcement for enhancement of tensile strength of the Epoxy/Glass composite. The response surface was successfully applied to determine the optimal operational process parameter such as $2.5 \%$ nanoclay content,700 gsm fabric density,800 rpm stirrer speed through hand layup technique. An increase of tensile strength by $29 \%$ was achieved over the neat epoxy composite. This improvement is due to the presence of exfoliated nanocomposite structure. X-ray diffraction (XRD) patterns shows that the nanoclay has orderly exfoliated in polymer matrix. SEM micrograph also revealed that the nanoclay particles are uniformly dispersed in polymer. It is further believed that the presence of stiffer nanoclay significantly reduced the surface crack propagation and controlled the damage area. A quadratic model, developed in terms of nanoclay content, fabric GSM and stirrer speed, to represent the tensile strength of the composite and the corresponding coefficients of independent variables was estimated by the application of Design Expert 7.1 trial version.

\section{References}

[1] Abrate, S, “Impact on laminated composites: recent advances”A Applied Mechanics Reviews, Vol. 47(11), pp. 517-544,1994.

[2] Alexander, M. and Dubois, P, "Polymer-layered Silicate Nanocomposites: Preparation, Properties and Uses of a New Class of Materials”, Materials Science and Engineering, Vol.28, pp.1-63,2000.

[3] Anderson, M, “Design of Experiments”, The Industrial Physicist,Vol.3, pp.24-26,1997.

[4] Bernd Wetzel, Frank Haupert, and Ming Qiu Zhang,"Epoxy nanocomposites with high mechanical and tribological performance”,Composite Science and Technology, Vol. 63, pp. 2055-2067,2003.

[5] Chowdhury, F.H. Hosur, M.V. and Jeelani, S, "Studies on the flexural and thermomechanical properties of woven carbon/nanoclayepoxy laminates”, Materials Science and Engineering. A, Vol. 421, pp. 298-306,2006.

[6] Gao. F, “Clay/polymer composites: the story”. Materials Today Vol.7(11), pp. 50-55,2004.

[7] Goldstein, N, “'Handbook of Nanophase Materials”, Marcel Dekker Inc, New York,1997.

[8] Guggenheim, Stephen, and Martin, R. T, "Definition of clay and clay mineral”, Journal report of the Clays and Clay Minerals Clay mineral nomenclature, American Mineralogist, Vol. 43, pp. 255-258,1995.

[9] Haque, A. Shamsuzzoha, M. Hussain, F and Dean, D, "'S2-Glass/epoxy polymer nanocomposites: Manufacturing, structures, thermal and mechanical properties”, Journal of Composite Materials, Vol.37, pp. 1821-1837,2003. 
[10] Hosur, M.V. Chowodhury, F.H. and Jeelani, S, “Low velocity impact response and ultrasonic NDE of woven carbon/epoxy_nanoclay nanocomposites”, Journal of Composite Materials, Vol.41, pp. 2195-212,2007.

[11] Kornmann, X, Rees, M. Thomann, Y. Necola, A. Barbezat, M. and Thomann, R, “Epoxy-layered silicate nanocomposites as matrix in glass fiber-reinforced composites”, Composites Science and Technology, Vol.65(10), pp. 2259-2268,2005.

[12] Lei Wang, A. Ke Wang, Ling Chen, Yongwei Zhang, and Chaobin He, "Preparation, morphology and thermal/mechanical properties of epoxy/nanoclay composite”, Composites: Part A, Vol. 37, pp. 1890-189,2006.

[13] Novak, B.M, "Hybrid Nanocomposite Materials-between inorganic glasses and organic polymers”, Advanced Materials, Vol.5,No.6, pp.422-433,1993.

[14] Ramanujam Sarathi, Ravindrakumar Sahu, and Danikas, M.G, “Understanding the mechanical properties of epoxy nanocomposite insulating materials”, Journal of Electrical Engineering, Vol. 60(6), pp.358-361.2009.

[15] Wang, Z. and Pinnavaia, T, "Hybrid Organic-Inorganic Nanocomposites: Exfoliation of Magadiite Nanolayers in an Elastomeric Epoxy”, Chemistry of Materials, Vol.10, pp. 1820-1826,1998. 